\title{
ANALYSIS OF SPOT-WELDING PITCH ON TOP HAT STRUCTURE AGAINST CRASHWORTHINESS CRITERIA
}

\author{
Harry Purnama ${ }^{1,2}$, Jos Istiyanto ${ }^{1}$ \\ ${ }^{1}$ Department of Mechanical engineering, University of Indonesia \\ ${ }^{2}$ Center of Technology for Machinery Industry \\ e-mail: harry.purnama@bppt.go.id
}

\begin{abstract}
The application of spot-welding in the automotive industry, especially the electricbased vehicle frame structure, has been optimized to meet passenger and battery compartment safety factors. The present numerical study of the electric-based vehicle frame structure with the top hat cross-sectional model validated the experimental results of reference, which then modified the spot-welding pitch to determine the crashworthiness effect and criteria. The numerical simulation results show that reducing spot-welding pitch in vertical direction can increase energy absorption (EA) by $1.70 \%-9.91 \%$, while bringing spot-welding pitch closer to the flange's outer edge can reduce its maximum force (Fmax) by $8.11 \%$ $21.67 \%$.
\end{abstract}

Keywords: Spot-welding; Top Hat Structure; Crashworthiness; Numerical Simulation; Electric Vehicle.

\section{INTRODUCTION}

The trend of environmentally sustainable vehicles is generating electric vehicle technologies that are supposed to overtake internal combustion-based vehicles. However, the development of electric vehicles is concerned with the safety factors for occupants and the battery compartment that could explode when an accident happens [1]. The safety factor of electric vehicles cannot be distinguished from the structural design of the joints of the vehicle frame.

The spot-welding in plate joints on vehicle frames is very dominant and still being carried out, even though there is a new plate connection method by combining lancing and shearing processes to assemble the crash box as an energy absorber due to frontal collision [2]. Considering the strength and lightness of vehicle frame structures, especially electric-based vehicles, is an important factor for the automotive industry in choosing spot-welding. It has been studied to find the number and layout of spotwelding on vehicle frame structures to balance structural performance and production costs [3] [4].
The thin-walled structure with a top hat crosssection is a simple model of frame components in a vehicle has been investigated for crash worthiness effects [5-7]. In a parametric study using finite element method, Dimas [8] modelling beam elements and solid elements as spotwelding with the ratio of the spot-welding pitch to the half folding length of the top hat can affect the crashworthiness characteristics. It also varies the length of top hat flange applied to the S-rail structures [9].

In the end, the purpose of this present study is to determine the effect of vertical and horizontal spot-welding pitch on energy absorption (EA), maximum force (Fmax), average force (Fmean) so that it can consider the application of structural design to electric-based vehicle frames, especially the top hat-shaped frame structure.

\section{METHODS}

This numerical simulation is based on an experimental study from reference [10], then the top hat geometric modelling can be seen as in Figure 1 with detailed dimensions in Table 1. While the materials also used refer to references [10] are mild steel FEE355. 
An answer to this study aims to modify the spot-welding pitch both parallel (p) and perpendicular $(x)$ direction of the axial impact to determine crashworthiness characteristics. As a reference for that, the spot-welding pitch in the parallel direction of the axial impact called the vertical pitch ( $p 1, p 2)$, and the spot-welding pitch in the perpendicular direction of the axial impact, called the horizontal pitch $(x 1, x 2, x 3)$, where the value of horizontal pitch measured from the edge of outer flange. Details of the value of spotwelding pitch can be seen in Table 2 .
In contrast to the numerical simulation in the reference [10], which uses the LS-Dyna software, but as seen in Figure 2. numerical simulation of this study uses a quasi-static explicit time integration ABAQUS by modelling the type of shell element S4R on the top hat with mesh size of 2x2 mm and R3D4 in the section. Impactor and base support. As mentioned in the reference [11], spot-welding has used the rigid-node model as the best model for modelling spot-welding contacts.
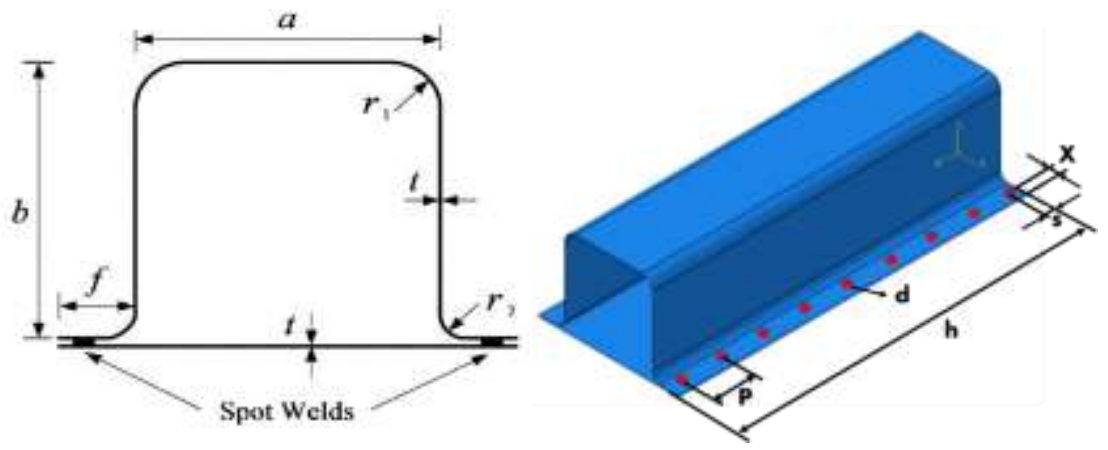

Figure 1. Geometry of top hat cross-section [10]

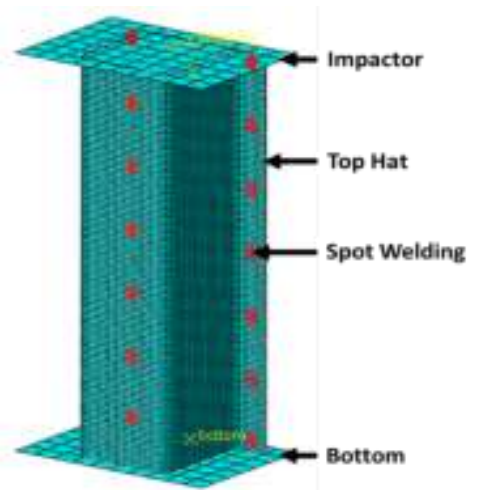

Figure 2. Numerical simulation model.

Table 1. Dimension detail of top hat.

\begin{tabular}{cccccccccc}
\hline $\begin{array}{c}\text { Wall } \\
\begin{array}{c}\text { Thickness } \mathrm{t} \\
(\mathrm{mm})\end{array}\end{array}$ & $\begin{array}{c}\text { Width a } \\
(\mathrm{mm})\end{array}$ & $\begin{array}{c}\text { Width b } \\
(\mathrm{mm})\end{array}$ & $\begin{array}{c}\text { Height h } \\
(\mathrm{mm})\end{array}$ & $\begin{array}{c}\text { Flange f } \\
(\mathrm{mm})\end{array}$ & $\begin{array}{c}\text { Inner } \\
\text { radius } \mathrm{r}_{1} \\
(\mathrm{~mm})\end{array}$ & $\begin{array}{c}\text { Outer } \\
\text { radius } \mathrm{r}_{2} \\
(\mathrm{~mm})\end{array}$ & $\begin{array}{c}\text { Edge } \\
\text { spacing } \\
\mathrm{s}(\mathrm{mm})\end{array}$ & $\begin{array}{c}\text { Spot-weld } \\
\text { diameter } \mathrm{d} \\
(\mathrm{mm})\end{array}$ & $\begin{array}{c}\text { Spot-weld } \\
\text { spacing } \mathrm{p} \\
(\mathrm{mm})\end{array}$ \\
\hline 1.5 & 50 & 50 & 200 & 15 & 6 & 4 & 5.5 & 6 & 27 \\
\hline
\end{tabular}

Table 2. Modification of spot-welding pitch.

\begin{tabular}{ccccc}
\hline $\begin{array}{c}\text { Spot-weld spacing } \\
\text { vertical p1 }(\mathrm{mm})\end{array}$ & $\begin{array}{c}\text { Spot-weld spacing } \\
\text { vertical p2 }(\mathrm{mm})\end{array}$ & $\begin{array}{c}\text { Spot-weld spacing } \\
\text { horizontal x1 }(\mathrm{mm})\end{array}$ & $\begin{array}{c}\text { Spot-weld spacing } \\
\text { horizontal x2 }(\mathrm{mm})\end{array}$ & $\begin{array}{c}\text { Spot-weld spacing } \\
\text { horizontal x3 }(\mathrm{mm})\end{array}$ \\
\hline 27 & 13.5 & 7.5 & 6 & 4.5 \\
\hline
\end{tabular}


The simulation's crashworthiness criteria is extracted from the force-deformation curve to give the following equations, which are commonly described in various references.

Energy absorption (EA):

$E A=\int_{0}^{\delta_{\max }} F(\delta) d \delta$

Where $\mathrm{F}$ is instantaneous crushing force, $\delta$ is vertical displacement of impactor mass.

Average Force (Fmean):

Fmean $=\frac{E A}{\delta_{\max }}$

\section{VALIDATION}

The numerical simulation result in this study shows good agreement with experimental and simulation results conducted by [10]. In Figure 3. the force-deformation curve shows the peak force of the three tests shows a slight difference, the simulation test conducted by Song [10] is the highest at $113 \mathrm{kN}$, compared to the experimental test of $107 \mathrm{kN}$, while the simulation test in the current study is the lowest at $104 \mathrm{kN}$. If

it is related to the structural strength, it should be that both simulations and experimental tests show the same results, this difference could be that the simulation test parameters cannot be close to the experimental test parameters due to geometric imperfections, strain rate of material properties, discretization, contact model, etc. Whereas in Table 3, the average force (Fmean) results show that the error result between the simulation of present study and experimental is $5.85 \%$, this value is better than the simulation and experimental results conducted by Song [10] which is equal to $13.37 \%$.

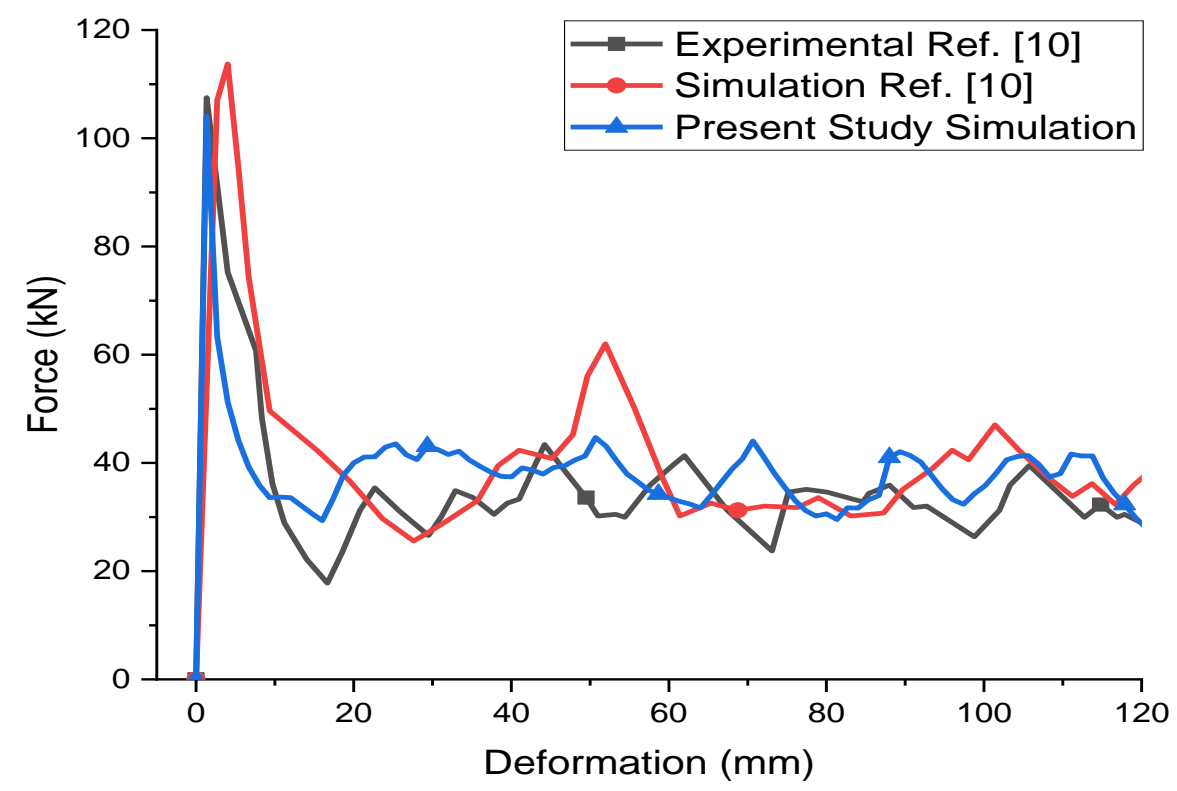

Figure 3. Force-deformation curve of experimental and simulation.

Table 3. Average force (Fmean).

\begin{tabular}{ccccc}
\hline $\begin{array}{c}\text { Experimental } \\
(\mathrm{kN})\end{array}$ & $\begin{array}{c}\text { Simulation } \\
(\mathrm{kN})\end{array}$ & $\begin{array}{c}\text { Present study } \\
\text { Simulation }(\mathrm{kN})\end{array}$ & $\begin{array}{c}\text { Error experimental- } \\
\text { simulation }(\%)\end{array}$ & $\begin{array}{c}\text { Error experimental- } \\
\text { present study simulation } \\
(\%)\end{array}$ \\
\hline 36.20 & 41.04 & 38.32 & 13.37 & 5.85 \\
\hline
\end{tabular}




\begin{tabular}{|c|c|c|c|c|c|c|}
\hline Folding & $P_{1} X_{1}$ & $P_{1} X_{2}$ & $P_{1} X_{3}$ & $P_{2} X_{1}$ & $P_{2} X_{2}$ & $P_{2} X_{3}$ \\
\hline $\begin{array}{l}\text { First } \\
\text { Folding }\end{array}$ & & & & & & \\
\hline $\begin{array}{l}\text { Final } \\
\text { Folding }\end{array}$ & & & & & & \\
\hline
\end{tabular}

Figure 4. First and final folding of top hat structure.

\section{RESULTS AND DISCUSSION}

The simulation results in Figure $\mathbf{4}$ show that with a spot-welding pitch (P1) of $27 \mathrm{~mm}$, the first folding starts at the top of the top hat. Whereas at the spot-welding pitch (P2) of $13.5 \mathrm{~mm}$, the first folding starts at the centre of the top hat structure. This shows that the tighter the spot-welding pitch will change the first folding location although it can be ascertained that the folding mode's shape is asymmetric as mentioned in the reference [8].

Specifically, Figure 5 shows that from the simulation results between $\mathrm{P} 1 \mathrm{X} 1, \mathrm{P} 1 \mathrm{X} 2$, and $\mathrm{P} 1 \mathrm{X} 3$, different shapes in the first folding, which $\mathrm{P} 1 \mathrm{X} 1$ experiences the opposite folding direction, the top hat looks open, while on P1X2, P1X3 has a unidirectional folding so that not open. From the results, the construction of spot-welding that is closer to the edge of the flange will create a perfect direction of the folding and allow the decrease in Fmax.

In the curve of Figure 6, there is a significant difference between the spot-welding pitch model
$\mathrm{P} 1$ and $\mathrm{P} 2$, where the curve shows that for $\mathrm{P} 1$ after the maximum force occurs, the curve tends to slope at the height of $44 \mathrm{kN}$ and to reach the second peak the deformation distance is $16 \mathrm{~mm}$. In comparison, for P2, after the maximum force of the curve height is more than $60 \mathrm{kN}$ and the second peak distance of the deformation distance is $40 \mathrm{~mm}$, almost twice the deformation distance of the P1 model.

The detailed values in Table 4 show that the spot-welding pitch $\mathrm{P} 1$ has EA, Fmax, Fmean smaller than the spot-welding pitch P2. This condition is also same as the reference condition [8], although Tarigopula [12] states that the amount of spot-welding, which means the pitch of spot-welding, does not have much effect on the value of EA, Fmax and Fmean.

In more detail, the effect of horizontal spotwelding distances $\mathrm{X} 1, \mathrm{X} 2$, and $\mathrm{X} 3$ is that the closer the spot-welding is to the flange's outer edge, the lower the value of EA, Fmax, and Fmean

Table 4. Value of EA, Fmax, Fmean for each spot-welding pitch

\begin{tabular}{cccc}
\hline Spot-welding Pitch & EA (kJ) & $\begin{array}{c}\text { Fmax } \\
(\mathbf{k N})\end{array}$ & Fmean (kN) \\
\hline P1X1 & 4.62 & 104.03 & 38.32 \\
P1X2 & 4.18 & 95.86 & 34.73 \\
P1X3 & 4.12 & 81.48 & 34.24 \\
& & & \\
P2X1 & 4.70 & 129.41 & 39.22 \\
P2X2 & 4.64 & 122.25 & 38.64 \\
P2X3 & 4.36 & 118.92 & 36.32 \\
\hline
\end{tabular}





Figure 5. First folding phenomena of top hat.

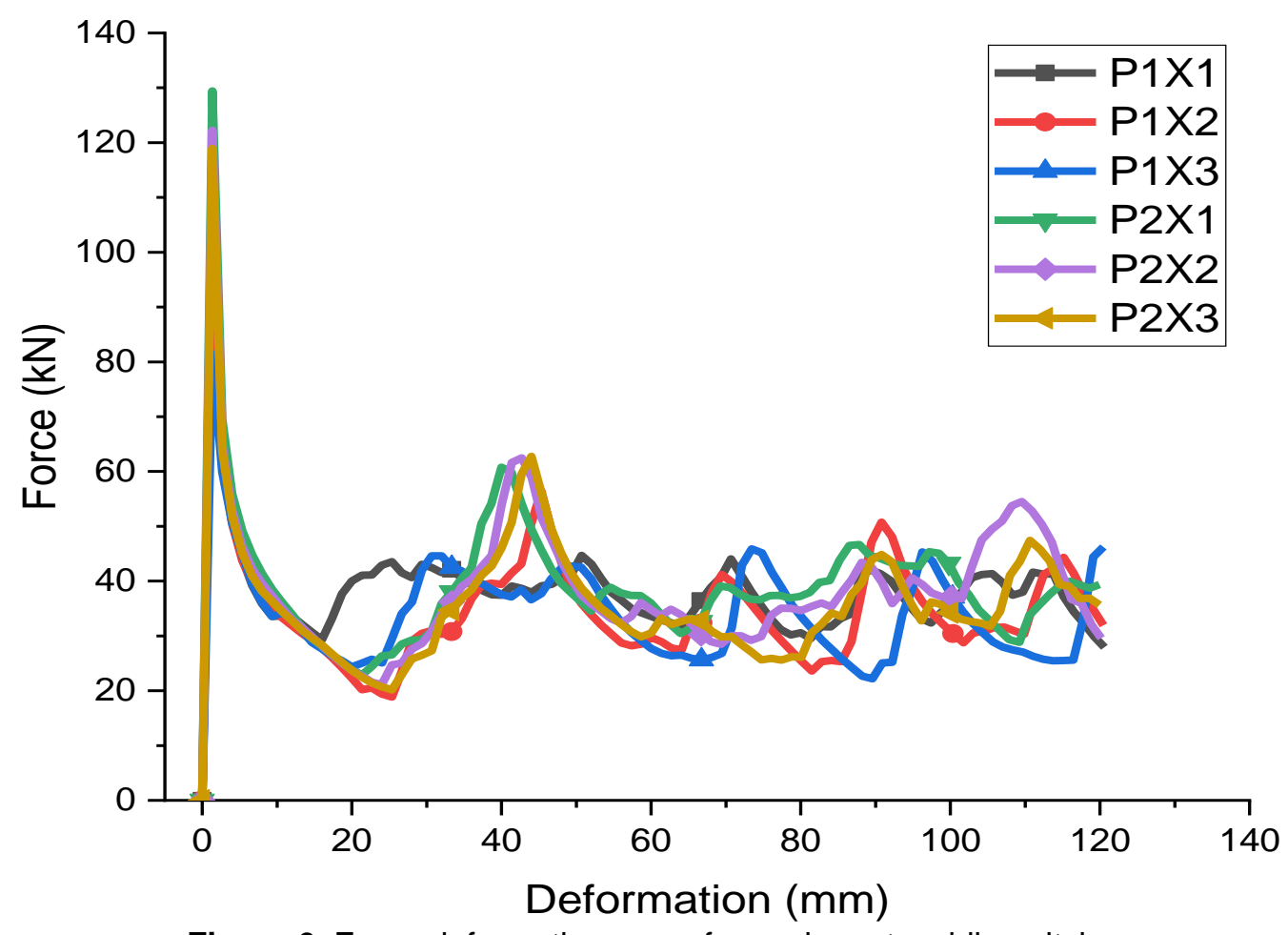

Figure 6. Force-deformation curve for each spot-welding pitch. 


\section{CONCLUSION}

Numerical simulations have been carried out on experimental and simulation results in reference [10] with acceptable results with an error of $5.85 \%$. Meanwhile, the spot-welding pitch investigation found that reducing the spotwelding pitch vertically can increase the value of the crashworthiness criteria. This is related to the theoretical of half wavelength $(\mathrm{H})$ that should occur in the top hat structure studied by White [13]. where the first folding follows the value of half wavelength $(\mathrm{H})$

Modifying the spot-welding pitch horizontally can reduce the value of the crashworthiness criteria and the modification that is often used, namely by using a crush initiator. This can be an input for further research to combine the pitch between spot-welding and crush initiator to obtain optimum crashworthiness criteria.

\section{AUTHOR INFORMATION}

\section{Corresponding Authors}

First author:

Email: harry.purnama@bppt.go.id.

Phone: +628562882619

Second author:

Email: josist@eng.ui.ac.id

\section{Author Contributions}

First Author and Second Author have contributed equally to this work to design the model and the computational, numerical framework and analysed the data. All authors contributed to the final version of the manuscript.

\section{ACKNOWLEDGMENTS}

The author would like to thank the Ministry of Research and Technology-BRIN for financial support through the 2019 scientific scholarship. (SK Number No: B-129-D3.1-KD.01.00-2019).

\section{REFERENCES}

[1] S. Arora, W. Shen, and A. Kapoor. "Review of mechanical design and strategic placement technique of a robust battery pack for electric vehicles", In: Renewable and Sustainable Energy Reviews, 2016, 60, pp. 1319-1331.
[2] D. F. Silva, C. Silva, I.M. Bragança, C.V. Nielsen, L. M. Alves, \& P.A. Martins. "On the performance of thin-walled crash boxes joined by forming", 2018, 11(7), pp. 1118.

[3] S. Yang, L. Yan, and C. Qi. "An adaptive multi-step varying-domain topology optimization method for spot weld design of automotive structures", 2019, 59, pp. 291310.

[4] A. B. Ryberg, L. J. S. Nilsson, and M. optimization. "Spot weld reduction methods for automotive structures", 2016, 53(4), pp. 923-934.

[5] L. Duan, Z. Du, H. Jiang, W. Xu, and Z Li. "Theoretical prediction and crashworthiness optimization of top-hat thin-walled structures under transverse loading", 2019, 144, pp. 106261.

[6] G. Sun, J. Tian, T. Liu, X. Yan, and X. Huang. "Crashworthiness optimization of automotive parts with tailor rolled blank", 2018, 169, pp. 201-215.

[7] G. Zheng, Z. Fan, H. Zhang, and P. Zhou. "Crashworthiness Optimization of SteelMagnesium Hybrid Double-Hat-Shaped Tubes", 2018, 1(3), pp. 247-254.

[8] A. Dimas, T. Dirgantara, and L. Gunawan. "The Effects of Spot Weld Pitch to the Axial Crushing Characteristics of Top-Hat Crash box", In: Applied Mechanics and Materials. 2014.

[9] Q. Zhou, X. Wu, Y. Xia, and W. Cai. "Spot weld layout optimization of tube crash performance with manufacturing constraints", 2014, 136(1).

[10] H. W. Song, Z. J. Fan, G. Yu, Q. C. Wang, and A. Tobota. "Partition energy absorption of axially crushed aluminum foam-filled hat sections", 2005, 42(9-10), pp. 2575-2600.

[11] Y. Xiang, Q. Wang, Z. Fan, and H. Fang. "Optimal crashworthiness design of a spotwelded thin-walled hat section", 2006, 42(10), pp. 846-855.

[12] V. Tarigopula, M. Langseth, and O.S. Hopperstad. "Axial crushing of thin-walled high-strength steel sections", 2006, 32(5), pp. 847-882.

[13] M.D. White, N. Jones, and W. Abramowicz. "A theoretical analysis for the quasi-static axial crushing of top-hat and double-hat thinwalled sections", 1999, 41(2), pp. 209-233. 